\title{
A general diagram of the human genome
}

\author{
Ricardo Cruz-Coke
}

\begin{abstract}
A general diagram of the whole structure of the human genome is drafted on a logarithmic metric scale located in the radius of a circle showing a full haploid set of chromosomes. A base pair scale of DNA is displayed in circumferences at different orders of magnitude from one metre down to one picometre $\left(10^{-12} \mathrm{~m}\right)$.
\end{abstract}

The introduction of DNA sequencing techniques in conjunction with cytogenetics, immunogenetics, and biochemical genetics has extended the range of medical genetics to the whole structure of genetic material. ${ }^{1}$ The genome, the haploid set of chromosomes with the genes they contain, is often explored across a wide range of magnitudes from 1 metre down to $10^{-12}$ picometres using different yardsticks, without considering a global overview of the genetic material. The purpose of this paper is to construct a general diagram to map the whole structure of the human genome along all the levels of magnitude.

The haploid genome contains around 3 billion base pairs of DNA $\left(2 \cdot 8 \times 10^{9}\right)$ which is $2 \cdot 8$ million kilobases $(\mathrm{kb})$ or 2.8 thousand megabases $(\mathrm{Mb})$. The size range of single genes varies between $1 \mathrm{~kb}$ and over $1 \mathrm{Mb}$. In the metre scale the haploid genome has a thickness of 2 nanometres $\left(2 \times 10^{-9} \mathrm{~m}\right)$ and a length of 170 centimetres; it is packed 5000 times into the chromosomes located at the $10^{-6}$ metre level (micron). ${ }^{2}$ The picometre level $\left(10^{-12} \mathrm{~m}\right)$ describes the position of the atoms of the DNA molecule where the mutations take place. Considering these astronomical magnitudes our problem is how to map in a single diagram the giant size of these two scales of measurement.

Medical Genetics Unit, Hospital J J Aguirre, University of Chile, Santiago, Chile.

R Cruz-Coke

Received for publication 20 November 1989.

Accepted for publication 18 December 1989.
The figure shows an attempt to design a diagram of the whole structure of the human genome on a logarithmic metric scale located in the radius of a circle; it includes an idiogram showing a haploid set of chromosomes in a ring at the $10^{-5}$ level. ${ }^{3} \mathrm{~A}$ base pair scale of DNA is displayed on the opposite radius of the metric scale, correlating the base pairs, kilobases, and megabases with a basic standard measurement of 2800 megabases of the total chromosome map given by McKusick. ${ }^{4}$ In the middle rings, the DNA levels correlate with nanometres $\left(10^{-9} \mathrm{~m}\right)$ and are measured in kilobases. The base sequences are measured in base pairs at the $10^{-11} \mathrm{~m}$ level. The atomic level at $10^{-12}$ picometres displays $\mathrm{C}, \mathrm{N}, \mathrm{O}$, and $\mathrm{H}$, the raw material of the genome at the bottom of the microcosm.

In order to explain the use of this diagram, the figure displays the haemoglobin genome in full at all levels of magnitude. The chromosome loci $H B B C$ (11p15.5) and $H B A C(16 \mathrm{pl3} .3)$ are shown at the chromosome level. ${ }^{5}$ The gene clusters $\beta$ globin-like and $\alpha$ globin-like are shown on the $10^{-8}$ ring covering $50 \mathrm{~kb}$ and $30 \mathrm{~kb}$ of the total scale of $2800 \mathrm{~kb}$. The single genes in these clusters are displayed at the $10^{-9}$ level in a more refined scale of $280 \mathrm{~kb}$, where it is possible to locate every gene to the nearest $1 \mathrm{~kb}$. Also, the arrow illustrates the ontogenic process of linear transcription of embryonic, fetal, and adult $\mathrm{Hb}^{6}$ The base sequences of the mutation $\mathrm{Glu} \rightarrow \mathrm{Val}$ (GAG $\rightarrow$ GTG) which are mutated in the $\beta$ gene are displayed at the $10^{-11}$ metre level and measured in base pairs.

An advantage of this general diagram of the human genome is to display usefully in a single figure the complete distribution of the characteristics of a given genetic locus or a complex genetic system. Also, both scales of measurement are correlated at different orders of magnitude, locating exactly the position of every gene in the degree scale of the circumference of the diagram. Moreover, the diagram displays a continuous base pair scale from the first to the last 2800th megabase, establishing the possibility of identifying in the outer rings every single gene to the 


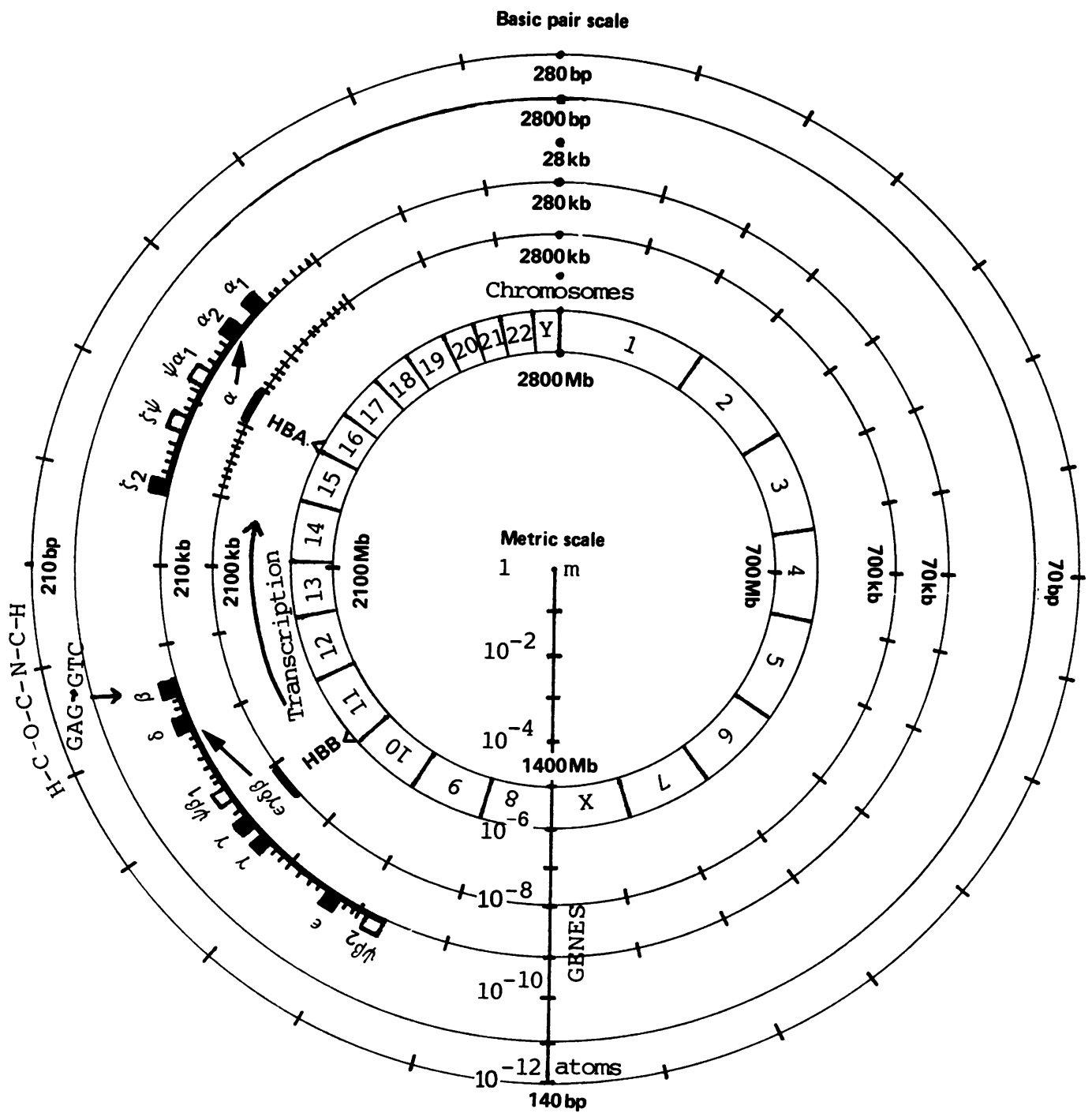

General diagram of the human genome in semilogarithmic metric and base pair scales, displayed around a circular idiogram. The base pair scale is graduated approximately to McKusick's gene map. Gene clusters and single genes are displayed facing corresponding chromosome loci.

exact kilobase and to the nearest degree in the standard scale of a circle.

1 Harper PS. Molecular genetics as a diagnostic service. $f$ Med Genet 1989;26:217-8.

2 Collins FS. The human gene map. Medical genetics 1987 syllabus.

Foundation for Advanced Education in the Sciences. Bethesda: NIH, 1987:156-73.
3 Cruz-Coke R. Translocation chromosome map of oncogenes. $f$ Med Genet 1987;24:111-2.

4 McKusick VA. Mendelian inheritance in man. 8th ed. Baltimore: Johns Hopkins University Press, 1988.

5 Buckle VJ, Higgs DR, Wilkie AOM, Super M, Weatherall DJ. Localisation of human $\alpha$ globin to 16 p13.3 $\rightarrow$ pter. $\mathcal{F}$ Med Genef
$1988 ; 25: 847-59$.

6 Schechter AN. Hemoglobin: genes, proteins and diseases. Medical genetics 1987 syllabus. Foundation for Advanced Education in the Sciences. Bethesda: NIH, 1987:10-33. 